\title{
A luta pelo amor e o amor pela luta: notas sobre a cerimônia coletiva de uniões homoafetivas no Rio de Janeiro
}

\author{
Jimena de Garay Hernández \\ Mestranda em Psicologia Social (UERJ) \\ jime_degaray@hotmail.com \\ Daniele Andrade da Silva \\ Mestranda em Psicologia Social (UERJ) \\ danieleandradepsi@gmail.com \\ Anna Paula Uziel \\ Doutora em Ciências Sociais (Unicamp) \\ Professora da Universidade do Estado do Rio de Janeiro \\ uzielap@gmail.com
}

\begin{abstract}
Resumo Este trabalho apresenta uma série de reflexões surgidas na cerimônia coletiva de união estável homoafetiva que aconteceu no dia 22 de junho de 2011, na Superintendência de Direitos Individuais, Coletivos e Difusos do Estado do Rio de Janeiro. Esse cenário é um campo fértil de reflexões sobre fenômenos psicossociais que dizem respeito às homossexualidades, travestilidades e transexualidades. As posições favoráveis ao contrato de união estável entre pessoas do mesmo sexo argumentam que a reivindicação desse direito por parte da coletividade LGBT satisfará desejos de segurança e proteção, relacionados à cidadania. A exigência de acesso à instituição da união estável, tida por conservadora e reprodutora da heteronormatividade e do patriarcado, tem sido lida por alguns como uma transformação dessa instituição; no entanto, ainda para outros e outras, essa integração equivaleria a um movimento de domesticação heterossexista.
\end{abstract}

Palavras-chave: união homoafetiva, Estado, identidade, coletividade.

\section{Introdução}

— ste trabalho apresenta uma série de reflexões provocadas pela Darticipação na cerimônia coletiva de união estável homoafetiva que aconteceu no dia 22 de junho de 2011, na Superintendência de Direitos Individuais, Coletivos e Difusos do Estado do Rio de Janeiro (SuperDir), ${ }^{1}$ situada no prédio da Central do Brasil. Esse evento, organizado pela SuperDir, marca um importante avanço na luta pela conquista dos direitos da população LGBT e foi possibilitado pela decisão unânime do Supremo Tribunal Federal (STF), em maio de 2011, a respeito da legalização da união entre pessoas do mesmo sexo.

1. Agradecemos à SuperDir pelo apoio logístico oferecido para o desenvolvimento dessa pesquisa. 


\section{Convidado principal: a cidadania}

Tal cerimônia constitui um campo fértil de reflexões sobre fenômenos psicossociais que dizem respeito às homossexualidades, travestilidades e transexualidades, pois alguns entrecruzamentos tornam-se visíveis, como a valorização das relações mediadas pelo Estado, percebidas aí como uma conquista de direitos, especialmente no caso da união estável entre pessoas do mesmo sexo.

Assim, destaca-se a importância política do reconhecimento jurídico da união estável entre pessoas do mesmo sexo, embora se verifique que o estabelecimento e permanência de tais relações conjugais não passem, ou não necessitem passar, pelo crivo do reconhecimento legal. Nesse sentido, o que se coloca em discussão é como uma decisão do Estado a respeito do contrato firmado entre duas pessoas passa a defini-las como sujeitos políticos. O que nos parece, nesse caso, é que o fato de poder estabelecer um contrato regulado juridicamente com outra pessoa afeta a percepção de cada um dos envolvidos como cidadão de direitos, mesmo entre aqueles que não possuem expectativa em relação à aprovação legal. Cabe observar que esse mecanismo que surge aqui parece se restringir às relações homossexuais. Dadas as especificidades, não seria errado afirmar que essa ideia não povoa o pensamento de uma pessoa ou um casal heterossexual, uma vez que essa afirmação é tida como natural, sendo praticamente compulsória. Porém, para as pessoas que se relacionam com outras do mesmo sexo, tal afirmação é um logro para sua cidadania e um símbolo de reconhecimento do estar incluído na pólis (Vale de Almeida, 2007).

O que se observou durante a cerimônia de união estável foi a forte presença desse discurso de conquista política, tanto nas falas oficiais quanto nas dos casais, que se mostravam satisfeitos com a decisão do STF. Destacamos aqui o discurso proferido durante a cerimônia pelo Superintendente de Direitos Individuais, Coletivos e Difusos, Cláudio Nascimento:

\footnotetext{
[...] É pra isso que estamos aqui, para dar sentidos aos nossos amores, para dar sentido ao valor de liberdade, para dar sentido à República de todos e de todas, para todos e todas, em todos e todas, para dar sentido a nossa luta por um país livre, democrático e igualitário.
}

De forma parecida, ouvimos esse tipo de argumento dos casais:

[...] É uma felicidade indescritível, é a realização de um sonho, a realização dos direitos civis, a construção de família, é tudo o que a gente sempre quis que a sociedade reconhecesse. (Lésbica, 38 anos, assistente social)

$\mathrm{Na}$ oportunidade, observamos que o impacto pessoal se misturava com a importância coletiva. Por uma parte, realizava-se um contrato entre duas pessoas que ao se unirem faziam jus a direitos individuais, tais como a preservação do patrimônio e o acesso a direitos conjugais, como participação em plano de saúde da parceira ou do parceiro. Chamou-nos a atenção o fato de o desembargador ter oficializado a união estável de cada um dos 43 casais separadamente. Por outra parte, porém, a cerimônia foi realizada em um espaço que reunia diversos casais, em caráter de cerimônia coletiva e em que predominava o discurso da comunidade LGBT. Assim, naquele espaço se misturava a emoção singular de cada casal, uma vez que marcava simbolicamente uma cerimônia de casamento nos moldes tradicionais e que, ao mesmo tempo, representava um importante avanço nas lutas da comunidade LGBT; um avanço para a coletividade que garantia satisfação individual.

Paralelamente, casos específicos eram colocados como ícones da batalha coletiva, tanto pelo movimento quanto pela mídia. Um exemplo emblemático foi a presença de Liorcino Mendes e Odílio Torres, ${ }^{2}$ um caso que atingiu grande visibilidade e que se tornou responsável pelo grande assédio midiático que atingiu o casal durante a cerimônia realizada no prédio da Central do Brasil.

A partir das falas dos organizadores da cerimônia, o registro coletivo da união civil parece sugerir um novo coming out, ${ }^{3}$ como movimento político. Assim, há uma tensão em torno do privado em que a vida ou uma parte dela vira uma militância. Algumas formas de sexualidade, normalmente consideradas parte do mundo privado, se incluem na discussão cotidiana de uma grande parte da sociedade, no momento em que o Estado reconhece - cumprindo seu papel de proteção de direitos e de integridade um relacionamento entre pessoas do mesmo sexo, em uma cerimônia pública (Carrarae Vianna, 2008; Dehesa, 2010; Miskolci, 2007).

\footnotetext{
2. "O primeiro casal gay de Goiânia a registrar sua união depois da decisão de reconhecimento do STF (Supremo Tribunal Federal) perdeu o direito de permanecer em união estável. O juiz da $1^{\text {a }}$ Vara da Fazenda Pública Municipal e Registros Públicos de Goiânia, Jeronymo Pedro Villas Boas, cancelou de ofício (ou seja, sem nenhum pedido) o contrato". Disponível em http://noticias.uol.com.br/cotidiano/ultimas-noticias/2011/06/19/ mesmo-com-decisao-do-stf-casal-gay-tem-uniao-estavel-cancelada-em-goias.htm. Acesso em: 21 de março de 2012.
}

3. O coming out é "o processo através do qual pessoas homossexuais reconhecem suas preferências sexuais e escolhem integrar esse conhecimento nas suas vidas pessoais e sociais" (Monteflores e Schultz, 1978, p. 59, tradução livre). 


\section{Sim, aceito?}

A nosso modo de ver, a forma como esse movimento promovido pelo Estado para a garantia da união civil legal foi construída pode ser associada com a construção da identidade. E o discurso parece se dirigir a um grupo cuja hegemonia não se percebia até chegarmos ao $7^{\circ}$ andar daquele prédio. Durante a cerimônia, observamos muitas formas de ser mulher, de ser homem, de ser transexual, de ser travesti, de ser lésbica, de ser gay, de ser masculina e feminina, de ser masculino e feminino.

Parece-nos que as identidades são flexíveis, pois, como assinala Stuart Hall (2001), podemos ter identidades contraditórias, deslocadas, incoerentes, em diferentes direções, que podem ser convertidas em pontos de conflito e mobilização política. As distintas posições do sujeito se transformam em um campo político onde acontecem lutas e afirmações de identidades culturais que se manifestam em diversas arenas políticas e na relação com os Estados. Além de perceber que as posições de gênero e sexuais se multiplicam, tornando impossível, assim, lidar com elas a partir de esquemas binários, o que se coloca em questão, nesse momento, é que as próprias fronteiras vêm sendo constantemente atravessadas e que o local social que muitos sujeitos ocupam é justamente a fronteira (Louro, 2001). No entanto, um discurso militante raramente escapa da construção de uma certa unidade para agrupar as pessoas.

Para Judith Butler (2005), a identidade homossexual deve ser questionada, ao entendê-la, não como um corpo duro e rígido, mas, sim, como uma performance. Camilo Albuquerque nos lembra como a autora assinala que

[...] a "heterossexualização do desejo" requer e institui a produção de oposições discriminadas e assimétricas entre "feminino" e "masculino", compreendidas como atributos expressivos de "macho" e "fêmea". $\mathrm{O}$ efeito substantivo do gênero seria performativamente produzido e imposto pelas práticas reguladoras da coerência de gênero. A identidade de gênero (relação "coerente" entre sexo, gênero, prática sexual e desejo) seria o efeito de uma prática reguladora que pode ser identificada como heterossexualidade compulsória. (Albuquerque, 2006, p. 161)

Autores como Michel Foucault (1977) têm questionado a naturalização dos desejos sexuais que não podem ser concebidos como entidades biológicas preexistentes, mas, sim, como constituídos no curso de práticas sociais específicas, determinadas pela tradição. Partindo da ideia de Foucault de que a sexualidade é um "dispositivo histórico", Guacira Lopes Louro conclui que ela é "uma invenção social, uma vez que se constitui, historicamente, a partir de múltiplos discursos sobre o sexo: discursos que regulam, que normatizam, que instauram saberes, que produzem verdades" (Louro, 2000, p. 12).

Na cerimônia, então, nosso cenário privilegiado, podia-se observar que os casais eram bastante diversos. Havia, por exemplo, uma mulher transexual casando-se com um homem; um homem transexual, que se assumia como homem, unindo-se a uma mulher heterossexual; casais de lésbicas tradicionalmente femininas, vestidas de branco ou champanhe, com buquês e vestidos iguais; casais de gays de idades aparentemente iguais, outros com uma marcada diferença etária, entre outras variações. Por outro lado, conhecemos um casal de lésbicas que, ainda quando se mostrava muito contente pelo momento, não queria legalizar a união em um contexto de "glamour", tal como elas descreveram o evento. Assim, podemos pensar que sempre se produzem novas modalidades de identidade, desejo e relacionamento. E no evento que estamos narrando, várias dessas modalidades, por tanto tempo renegadas, foram celebradas. Ainda que nem todas elas fossem contempladas na organização do evento, nem na formulação da conquista dos direitos, foi possível ver a singularidade no cotidiano que os casais atualizavam naquele momento.

No entanto, a presença de estereótipos de gênero despertou nossa atenção, através de movimentos corporais, expressões verbais e as próprias vestimentas usadas pelos casais, especialmente nos casais de lésbicas. Essa dicotomia de gênero tem sido enxergada pelo movimento feminista como uma manifestação da reprodução do machismo nas relações homossexuais (Almeida, 2005). Por sua vez, o movimento lésbico tem criticado o movimento feminista hegemônico por deixar de lado a questão da orientação sexual, marcando uma heteronormatividade, abandonando uma ideia central do feminismo: "o pessoal é político". Assim, é interessante conceber a orientação sexual como um assunto público e a lesbianidade como uma identidade política, não apenas como uma prática sexual (Almeida, 2005).

Diante disso, os organizadores do evento demonstraram enorme satisfação ao constatar que a visibilidade lésbica alcança um crescente movimento, pois cerca de $65 \%$ dos casais presentes na cerimônia eram compostos por lésbicas, mostrando sua importante participação na luta, antes predominantemente masculina, como afirmaram Sérgio Carrara e Adriana Vianna (2008). No entanto, seria interessante indagar se isso não aconteceu porque as mulheres, devido a diversos atravessamentos sociais, tradicionalmente demonstram um maior desejo em acessar o casamento, o que implicaria, para alguns e algumas, a tentativa de abraçar uma instituição que tem oprimido as 
mulheres durante tanto tempo. Não há consenso a respeito desses sentidos.

As posições favoráveis à união estável entre pessoas do mesmo sexo argumentam que a reivindicação desse direito por parte da coletividade LGBT satisfaria desejos de segurança e proteção, relacionados à cidadania (Vale de Almeida, 2007). Esses desejos, nas falas dos casais, estão vinculados aos benefícios como a saúde, o patrimônio, a herança, a declaração de renda e aos direitos relativos às filhas e filhos, como efeitos da legitimidade dessas uniões (Miskolci, 2007, Vale de Almeida, 2007). Isso, para muitas e muitos, consolida a coletividade LGBT como cidadãos e cidadãs de direitos, derrubando uma barreira para a obtenção da igualdade formal de gays e lésbicas. Essa exigência de acesso a uma instituição - tida por conservadora e reprodutora da heteronormatividade e do patriarcado - tem sido lida por alguns como uma transformação dessa instituição; no entanto, para outros e outras, essa integração equivaleria a um movimento de "domesticação heterossexista" (Rios, 2007; Vale de Almeida, 2007).

Miguel Vale de Almeida (2007) assinala os posicionamentos radicais a respeito da união homoafetiva: o feminismo lésbico e a esquerda radical propõem uma crítica à instituição do casamento, que estaria em contínua tensão com a defesa da igualdade de direitos. Esses setores defendem que é prioritário realizar uma transformação profunda na concepção do casamento, para depois iniciar a luta pelos demais direitos. Eles valorizam as experimentações conjugais e afetivas da população LGBT, afirmando que contribuem para produção de novas formas de relacionamento afetivo e familiar. Para essa concepção, a luta em favor do casamento entre pessoas do mesmo sexo resultará em uma estigmatização dos gays e lésbicas que não queiram formar parte da instituição do casamento, gerando uma distinção entre "gays de primeira", ou "gays bons" (casados) e "gays de segunda" ou "gays maus" (considerados promíscuos). Como argumenta Judith Butler (2005), os limites da legitimidade e ilegitimidade seriam modificados, mas não questionados em suas bases, portanto, produziriam, ao contrário, outras hierarquias, constituindo-se um mecanismo de normalização social.

Essa autora aponta, ainda neste sentido, que ao reivindicar do Estado o reconhecimento das relações não heterossexuais, boa parte do movimento lésbico e gay não percebe que está atribuindo a essa instância o poder de detentor de um direito que deveria ser concedido sem que a orientação sexual fosse levada em conta. Para a autora, essa concessão do Estado intensifica a normalização. Tomando, como exemplo, países como Alemanha e França, ela assinala ainda que "as propostas bem sucedidas de 'casamento gay' nem sempre têm um impacto direto sobre a legislação relativa à família" (Butler, 2005, p. 223). Muito desse posicionamento se deve ao temor que grande parte da sociedade parece apresentar, especialmente em relação à parentalidade exercida por homossexuais. Essas variações familiares, "além de serem consideradas perigosas para as crianças, colocam em risco as leis consideradas naturais e culturais que supostamente amparam a inteligibilidade humana" (p. 224). Ainda, ao incorporar a população LGBT à instituição do casamento, esses casais se enquadrariam em um logos heterossexual que preconiza a fidelidade, a exclusividade, a coabitação e exige deveres econômicos. Em outras palavras, se integrariam a uma instituição relacional empobrecedora (Miskolci, 2007), sem transformá-la nem transgredi-la (Facchini, 2005), além de que essa integração ocorreria somente através do Estado.

No evento referido, a imagem de um casal de bonequinhos e um casal de bonequinhas em cima do bolo provoca a ideia tradicional do casamento. Como argumenta Miguel Vale de Almeida (2007, p. 160): "as sociedades reproduzem-se e perpetuam-se - e com elas os significados culturais -, mas não se replicam simplesmente, como os beneficiários das hegemonias desejariam. E nesse jogo entre mudança e continuidade relativas, os materiais simbólicos vão sendo retrabalhados". As rupturas que o reconhecimento legal da união entre pessoas do mesmo sexo propõe convivem com a ideia do amor romântico e eterno e a complementaridade, o que pôde ser percebido em muitos momentos da cerimônia. A presença de elementos tradicionais como a chuva de arroz cobrindo os casais, as canções de fundo que enalteciam o amor eterno, os vestidos de noiva e declarações como "até que a morte nos separe" (proferidas por alguns casais) e "o que Deus uniu o homem não pode separar" - dito pelo desembargador Sirlo Darlan, que oficializou a cerimônia - deixam perceber a lógica tradicional e heterocêntrica que atravessa de forma significativa nossa sociedade.

O jogo entre transgressão e perpetuação de significados é bastante complexo, mas tentaremos dar conta de algumas das suas dobras. Primeiro, com respeito ao casamento e à família - vistos de forma crítica como instituições opressoras, especialmente das mulheres - consideramos importante avaliá-los a partir de uma perspectiva em que verdades dadas e inquestionáveis são desconstruídas. Essas instituições têm sido alvo de importantes transformações, o que faz com que não possam ser consideradas como estáticas e maciças.

A ideia da família e do casamento foi reformada pelas feministas que - ao afirmarem que as famílias são instituições sociais e, portanto, mutáveis - criticaram profundamente o patriarcado moderno e o seu controle na definição dos 
papéis dentro desse grupo social (Scott, 2005); também desmistificaram a família baseada em lógicas hierárquicas não igualitárias, vinculadas ao sexo e à idade (Mello, 2005), democratizando o casamento (Vale de Almeida, 2007) e incluindo-o na linguagem e no exercício dos direitos (Carrara e Vianna, 2008; Rios, 2007). Portanto, o movimento feminista tem um papel protagonista nessas transformações, mas ainda assim foi severamente criticado nas suas vertentes hegemônicas, por seus argumentos partirem de realidades de mulheres burguesas, brancas e ocidentais. Como exemplo, a feminista negra bell hooks (1984) argumenta que a família assumiu um papel de proteção importantíssimo para as mulheres negras escravas e trabalhadoras dos Estados Unidos que, de forma contrária às mulheres brancas, nunca estiveram limitadas ao espaço doméstico, mas trabalharam sempre fora dele, em lugares onde eram severamente discriminadas. Para elas, o lar era o espaço de segurança e a família sua principal proteção contra a opressão vivida fora dela. Aqui, é possível pensar que a configuração familiar dessas mulheres se organizava diferentemente daquela que as mulheres brancas compunham.

O ponto que se pretende destacar aqui é a importância da desnaturalização da instituição familiar. Junto com o feminismo, algumas análises etnometodológicas e antropológicas mostraram que, apesar de sua hegemonia simbólica, a família burguesa nuclear androcêntrica e heteronormativa nunca foi a regra (Miskolci, 2007). Portanto, a família é compreendida como uma instituição social, fruto de um acordo entre diferentes atores políticos, acerca dos quais agrupamentos conjugais ou parentais devem ser legitimados pela sociedade e protegidos pelo Estado (Mello, 2005).

Por sua parte, o casamento não é nem um conteúdo nem uma relação essencial, mas uma forma contratual que pode ou não ter certos conteúdos relacionais (Fassin, 2004). Assim, para David Schneider (1997), as aspirações de gays e lésbicas ao direito ao casamento não se estabelecem nem em uma postura assimilacionista, nem em um desejo de legitimação da homossexualidade, mas em sua pertença a uma cultura e a uma sociedade, ou seja, a um discurso hegemônico, cujos valores partilham. Os casais homossexuais podem ou não se estabelecer como unidades domésticas entre pessoas que se amam, tanto quanto os casais heterossexuais. Assim, é difícil afirmar que a família e o casamento são a única instituição opressora, que o gênero é o único vetor de discriminação e que todos esses elementos não possam ser transformados.

É importante considerar que o fato de ser homossexual não é em si mesmo transgressor ou subversivo. Como argumenta Eric Fassin (2004), a homossexualidade não é substancialmente diferente da heterossexualidade, pois todas e todos partilhamos os mesmos sistemas simbólicos significativos que incluem as concepções de complementaridade, amor romântico e outros elementos que observamos na cerimônia. Esse é o amor que vimos nos olhos cheios de lágrimas da filha de 22 anos, ao ver a sua mãe biológica e a companheira dela (ambas consideradas pela jovem como suas mães) jurando amor eterno. A pergunta que se coloca então é: Por que elas deveriam desafiar a "cultura do amor" mais do que um casal heterossexual? A transgressão aos conceitos de complementaridade, amor romântico e eterno é uma escolha política, não algo inerente a uma orientação sexual. Assim, uma pessoa ou um casal - ou um trio, ou uma família - heterossexual poderia esvaziar o conteúdo do casamento tanto quanto uma pessoa ou casal - ou um trio, ou uma família - constituído por pessoas homossexuais. As reflexões que a academia (psicossocial, antropológica etc.) e os movimentos sociais (feminista, LGBT etc.) formulam somente podem convidar a questionar a instituição casamento sem, no entanto, impor ou exigir que homossexuais, simplesmente por se relacionarem afetivo-sexualmente com pessoas do mesmo sexo, sejam transgressores de todas e quaisquer normas ou construções sociais.

\section{Reconhecimento da união homoafetiva: um elemento na luta contra a homofobia}

No meio do evento, dentro do icônico prédio da Central do Brasil, sede do Programa Rio sem Homofobia, e rodeadas de cartazes da campanha desse programa, pareceu-nos importante pensar no vínculo entre a união homoafetiva e o combate à homofobia como lutas políticas do movimento LGBT no Brasil.

A defesa dessas uniões é vista por muitas e muitos como uma forma de proteção contra a homofobia, representando avanços na legitimação e dignidade das vidas de pessoas homossexuais, contribuindo para a igualdade social, ao se reconhecer e aceitar outros tipos de afetividade, superando preconceitos e estigmas que se exercem no âmbito público (Vale de Almeida, 2007). Para Sílvia Ramos e Sérgio Carrara (2006), a união homoafetiva pode ser a expressão mais emblemática da ampliação de direitos, antes limitados aos heterossexuais, como forma de enfrentar a discriminação. Dada sua importância, o tema 
é defendido como bandeira política da comunidade LGBT, ainda que não hegemônica, visando à ampliação de direitos e à conquista plena de cidadania.

Durante a cerimônia, especialmente nos discursos oficiais, reforçou-se a ideia de que esse passo contribuirá para a diminuição da homofobia, sendo a celebração do afeto e do amor uma forma de quebrar os preconceitos, a violência e os assassinatos contra pessoas homossexuais. A própria visibilidade que o evento ganhou foi festejada por muitos integrantes da coletividade LGBT. A cobertura midiática bastante expressiva com destaque para as demonstrações públicas de afeto nos principais jornais do país, além da presença de travestis (alvos frequentes de atos homofóbicos) como recepcionistas do casamento deram conta do reconhecimento social que esse evento representou.

No entanto, a respeito dos limites de legitimidade que se comentava anteriormente, existem diferentes hierarquias sociais no universo homossexual, o que faz com que as práticas homofóbicas sejam complexas (Carrara e Vianna, 2006). Existe uma confluência de hierarquias de raça, cor, classe, gênero e outros fatores, como a prostituição. Ainda que a visibilidade da coletividade LGBT seja maior agora, e que ninguém esteja proibido a se unir legalmente, o que vai acontecer com os e as que escolham outros tipos de sexualidades? Em que forma essa nova medida jurídica afetará suas vidas?

Destarte, apesar de todo avanço que se possa perceber, a vida amorosa de gays e lésbicas ainda parece reduzida, para muitos setores da sociedade, à sexualidade, demandando assim uma forte necessidade de controle. Portanto, o que se coloca em questão é que embora a luta por direitos civis seja justa, o que não se pode deixar de verificar é que tal luta passou a se dar nos termos hegemônicos, tais como o casamento e a família. A reflexão sobre esse fato se faz necessária, uma vez que, ao mesmo tempo em que se observa uma domesticação das demandas de um movimento social, ainda se observa uma crescente esfera de intolerância por parte da sociedade (Miskolci, 2007).

No cenário brasileiro, em especial, embora possamos comemorar decisões vanguardistas do Poder Judiciário que versam, há tempos, sobre o reconhecimento da união estável homossexual, por exemplo, continua crescente o número de casos de violência homofóbica. A despeito de toda a barbárie desse cenário, o Poder Legislativo, fortemente influenciado por setores religiosos, ainda parece muito distante de entrar em um consenso acerca da criminalização da homofobia. A existência de partidos políticos religiosos, a chamada "bancada evangélica", também reflete uma dificuldade em separar o Estado da religião. Para o pesquisador Marcelo Natividade, "a ideia de um
Estado laico supõe uma separação entre religião e o secular. Mas quando há a possibilidade de os religiosos ocuparem cargos políticos, há uma reinserção dos valores religiosos na política" (Castilhos, 2007).

Portanto, concordamos com vários e várias ativistas e funcionários do governo entrevistados, segundo os quais são necessárias lutas políticas como o Projeto de Lei n. 122 que visa criminalizar a homofobia. Essa deve continuar sendo uma das principais lutas do movimento LGBT.

A alegria diante da decisão do Supremo Tribunal de Justiça não deve ofuscar a luta fundamental: o direito a exercer sexualidade em qualquer de suas modalidades. Como argumentam alguns autores, é importante "exigir respeito, mas não perder a irreverência GLBT e a afirmação da sexualidade; demandar a criminalização da homofobia, mas não a regulação da diversidade sexual" (Ramos e Carrara, 2006, p. 199).

Acreditamos que, dentro dessa perspectiva, é possível ver que a legitimação por parte do governo ou de outras instituições - a exemplo da religião umbandista manifestada na cerimônia pela presença de uma mãe-de-santo - é só uma das razões pelas quais um casal pode desejar acessar ao casamento. A diversidade de razões faz com que se pense na união homoafetiva como o que é: um direito, não uma obrigação. Como bem assinala Judith Butler, o casamento não deveria ser a única forma de aceder a direitos que qualquer pessoa deveria ter. Segundo argumenta $\mathrm{Mi}-$ guel Vale de Almeida,

[...] uma política sexual mais radical poderia reconhecer a pluralidade das experiências e identidades sexuais, mesmo as menos conhecidas ou aceitas em nossos dias. [...] Além disso, as demandas por direitos podem se dar em outros termos, os quais apontem para a aceitação de novas formas de relacionamento e a constituição de um novo direito relacional, mais imaginativo e aberto às possibilidades. (Vale de Almeida, 2007, p. 126)

Por isso, é importante ir além da igualdade ou a homogeneização para pensar na diversidade dentro do marco dos direitos humanos.

\section{Considerações finais}

A diversidade sexual não pode continuar sendo vista como uma massa homogênea, mas, sim, como uma dimensão que cruza as diferentes categorias sociais. Nesse sentido, como afirma Gloria Careaga (2006), reconhecer a heterogeneidade da coletividade LGBT é um desafio teórico e organizativo que deve se impulsionar. 


\section{Como argumenta Roger Rios:}

[...] é preciso desenvolver um "direito democrático da sexualidade", vale dizer, um exame, na perspectiva dos direitos humanos e dos direitos constitucionais fundamentais, das diversas normas jurídicas, cujo âmbito de proteção atenta para as varias manifestações da sexualidade humana. (Rios, 2007, p. 4)

Partilhamos da opinião de autores como Judith Butler que possuem uma visão crítica do casamento, contudo, é importante ponderar que, para transformá-lo, é necessário alcançar antes ainda uma igualdade de direitos. No momento em que uma relação de igualdade de direitos for estabelecida, será possível propor mudanças e discussões a respeito do valor do casamento (Vale de Almeida, 2007). Ainda que em alguns momentos nosso pensamento seja radical, os movimentos políticos devem ser, nesse momento, de apoio a eventos como a cerimônia a que assistimos, na qual algumas pessoas se uniram por amor, outras para reafirmar seus direitos - como são diversos os motivos para o casamento. A partir da igualdade de direitos, poder-se-á falar em transformação. A compreensão de que a família é uma construção sociocultural dinâmica, flexível, plástica e capaz de incorporar cada vez mais formas de manifestação de vínculos sexuais e afetivos entre seres humanos torna possível pensá-la não como algo natural e estático, mas, sim, como uma organização complexa e com direito a uma diversidade rica e crescente.

Pensar a família no contexto das relações amorosas estáveis entre pessoas do mesmo sexo talvez seja uma oportunidade singular para a compreensão dos limites e possibilidades de construção de uma família plurívoca, dessencializada de qualquer determinação "natural", em que a diversidade de formas possíveis de estruturação dos vínculos familiares tenha como substrato comum não apenas a preocupação com a reprodução biológica da espécie, mas, principalmente, a criação de condições que assegurem o bem-estar físico e emocional dos seres humanos em interação. (Mello, 2005, p. 40)

A cerimônia coletiva representou uma festa para o amor e, além de reconhecermos a diversidade dentro das formas de amor manifestadas, acreditamos que essa festa deveria celebrar qualquer tipo de amor, qualquer tipo de desejo, qualquer tipo de corpo, qualquer tipo de cidadania. Uma festa que brinda o amor pela diversidade, comemorada como uma conquista.

\section{Referências}

ALBUQUERQUE, Camilo. Além da pele. Um olhar antropológico sobre a body modification em São Paulo. Campinas, 2006. Dissertação (Mestrado em Antropologia Social) - Unicamp.

ALMEIDA, Guilherme. Da invisibilidade à vulnerabilidade: percursos do "corpo lésbico" na cena brasileira face à possibilidade de infecção por DST e Aids. Rio de Janeiro, 2005. Tese (Doutorado em Saúde Coletiva) - UERJ.

BUTLER, Judith. ¿El parentesco siempre es de antemano heterosexual? Debate feminista. Matrimonio homosexual familia homoparental, v. 32, ano 16, p. 3-36, 2005.

CAREAGA, Gloria. Huellas innegables de una lucha: las políticas públicas en torno a la diversidad sexual en México. In: CÁCERES, Carlos; CAREAGA, Gloria; FRANCA, Tim; PECHENY, Mario (Ed.). Sexualidad, estigma y derechos humanos, desafíos para el acceso a la salud en América Latina. Lima: Universidad Peruana Cayetano Heredia, 2006.

CARRARA, Sérgio; VIANNA, Adriana. “Tá lá o corpo estendido no chão...” a violência letal contra travestis no município do Rio de Janeiro. PHYSIS: Rev. Saúde Coletiva, v.16, n.2, p. 233-249, 2006.

CARRARA, Sérgio; VIANNA, Adriana. Os direitos sexuais e reprodutivos no Brasil a partir da "Constituição Cidadã”. In: OLIVEN, Ruben; RIDENTI, Marcelo; BRANDÂO, Gildo (Org.). A Constituição de 1988 na vida brasileira. São Paulo: Aderaldo e Rothschild, 2008.

CASTILHOS, Washington. Laicidade à prova. 2007. Disponível em: www.clam.org.br/publique/media/ laicidade_a_prova.pdf. Acesso em: 13 mar. 2010.

DEHESA, Rafael de la. Queering the public sphere in Mexico and Brazil: sexual rights movements in emerging democracies. Durham: Duke University Press, 2010.

FACCHINI, Regina. Sopa de letrinhas? Movimento homossexual e produção de identidades coletivas nos anos 90. Rio de Janeiro: Garamond, 2005.

FASSIN, Eric. Sociological question. An epilogue to “More or Less Together". In: WAALDIJK, Kees (Org.). More or less together. Levels of legal consequences of marriage, cohabitation and registered partnerships for different-sex and same-sex partners. A comparative study of nine European countries. Paris: INED, 2004.

FOUCAULT, Michel. Historia da sexualidade 1. A vontade de saber. Rio de Janeiro: Edições Graal, 1977.

HALL, Stuart. A identidade cultural na pós-modernidade. 6. ed. Rio de Janeiro: DP\&A, 2001. 
HOOKS, Bell. Feminist theory: from margin to center. Cambridge: South End Press, 1984/ 2000.

LOURO, Guacira Lopes. Pedagogias da sexualidade. O Corpo Educado. Belo Horizonte: Autêntica, 2000.

LOURO, Guacira Lopes. Teoria queer: uma política pósidentitária para a educação. Rev. Estudos Feministas, v. 9, n. 2, p. 541-553, 2001.

MELLO, Luiz. Novas famílias: conjugalidade homossexual no Brasil contemporâneo. Rio de Janeiro: Garamond, 2005.

MISKOLCI, Richard. Pânicos morais e controle social reflexões sobre casamento gay. In: MISKOLCI, Richard; ASSIS SIMÔES, Júlio (Org.). Dossier Quereres. Cadernos Pagu, n. 28, p. 101-238, 2007.

MONTEFLORES, Carmen; SCHULTZ, Stephen. Coming out: similarities and differences for lesbians and gay men. Journal of Social Issues, v. 34, n. 3, p. 59-72, 1978. RAMOS, Silvia; CARRARA, Sérgio. A Constituição da problemática da violência contra homossexuais: a articulação entre ativismo e academia na elaboração de políticas públicas. PHYSIS: Rev. Saúde Coletiva, Rio de Janeiro, v. 16, n. 2, p. 185-205, 2006.

RIOS, Roger. Notas para o desenvolvimento de um direito democrático da sexualidade. In: RIOS, Roger (Org.). Em defesa dos direitos sexuais. Porto Alegre: Livraria do Advogado, 2007.

SCHNEIDER, David. The power of culture. Notes on some aspects of gay and lesbian kinship in America today. Cultural Anthropology, v. 12, n. 2, p. 270-274, 1997.

SCOTT, Joan. La política familiar feminista. Debate feminista. Matrimonio homosexual familia homoparental, ano 16, v. 32, p. 37-51, 2005.

VALE DE ALMEIDA, Miguel. O casamento entre pessoas do mesmo sexo. Sobre "gentes remotas e estranhas" numa "sociedade decente". In: GROSSI, Miriam; UZIEL, Anna Paula; MELLO, Luiz (Org.). Conjugalidades, parentalidades e identidades lésbicas, gays e travestis. Rio de Janeiro: Garamond, 2007.

\title{
The fight for love and love for the fight: notes about the collective ceremony of homoaffective unions in Rio de Janeiro
}

\begin{abstract}
This paper presents a series of reflections that emerged from the collective ceremony of homoaffective stable union, which took place on June $22^{\text {nd }}, 2011$, at the Superintendence of Individual, Collective and Diffuse Rights of the State of Rio de Janeiro. This scenario is a fertile field of reflections about psychosocial phenomena which are related to homosexualities, transexualities and travestialities. The favorable positions to the stable union between same-sex couples argue that the claim of that right by the LGBT community will satisfy desires of security and safety, related to citizenship. The demand for access to the stable union institution, taken as conservative and reproductive of the heteronormativity and patriarchy, has been read by some as the transformation of that institution, nevertheless, for others, that integration would mean a heterosexist domestication movement.
\end{abstract}

Key-words: homoaffective union, State, identity, collectivity.

\section{La lucha por el amor y el amor por la lucha: apuntes sobre la ceremonia colectiva de uniones homoafectivas en Río de Janeiro}

\section{Resumen}

Este trabajo presenta una serie de reflexiones surgidas en la ceremonia colectiva de unión estable homoafectiva que tuvo lugar el 22 de junio de 2011, en la Superintendencia de Derechos Individuales, Colectivos y Difusos del Estado de Río de Janeiro. Este escenario es un campo fértil de reflexiones sobre fenómenos psicosociales que hablan acerca de las homosexualidades, travestilidades y transexualidades. Las posiciones favorables al contrato de unión estable entre personas del mismo sexo argumentan que la reivindicación de dicho derecho por parte de la colectividad LGBT satisfará deseos de seguridad y protección, relacionados con la ciudadanía. La 
exigencia de acceso a la institución de la unión estable, considerada como conservadora y reproductora de la heteronormatividad y del patriarcado, ha sido leída por algunos como una transformación de dicha institución; sin embargo, para otros y otras, esa integración equivaldría a un movimiento de domesticación heterosexista.

Palavras-clave: unión homoafectiva, Estado, identidad, colectividad.

Data de recebimento do artigo: 26/03/2012

Data de aprovação do artigo: 20/07/2012 